\title{
Defectoscopy of conductive structures
}

\author{
A.V. Myatezh \\ Novosibirsk State Technical University \\ Novosibirsk, Russian Federation \\ user_m_82@mail.ru
}

\author{
B.V. Malozyomov \\ Novosibirsk State Technical University \\ Novosibirsk, Russian Federation \\ borisnovel@mail.ru
}

\begin{abstract}
A method of eddy-current defectoscopy of graphite electrodes is considered in the article. Imitation modeling of electromagnetic processes was performed, and a device based on a microcontroller for monitoring the integrity of the graphite electrodes was developed. The device has electrotechnical characteristics with a smaller time cycle of measurement.
\end{abstract}

Keywords - nondestructive control, eddy-current analysis, device for the control of the integrity, defectoscopy, nonmagnetic materials, graphite

\section{INTRODUCTION}

The problem of nondestructive quality control and integrity of graphite products is open now. There are various methods of defectoscopy of materials. For the researching of integrity, a nonconducting electric current of materials is suitable: acoustic, radiation, infrared, radio wave, electronoptical (partial discharges), capillary defectoscopy, etc. For researching the current-conducting materials, magnetic [1], eddy-current [2], electrospark [3] and thermoelectric defectoscopy [4] can also be used.

The graphite, which is used as electrodes [5] in arc steelsmelting furnaces, is the substance having high conductivity of about $0.125 \mathrm{MS} \cdot \mathrm{m}$, which is smaller than that of copper about 400 times.

Now ultrasonic (acoustic) defectoscopy is often used for quality control of electrodes of arc steel-smelting furnaces (Fig. 1) [6].

Lack of the ultrasonic method is the high coefficient of attenuation of acoustic waves in material, which is strongly complicating its application to electrodes, which diameter exceeds 1 meter, causes increased wear of piezo-acoustic sensors of the control element as well [7].

When choosing a method of defectoscopy, it is necessary to take the most characteristic properties of a controlled product into account [8].

Graphite does not have transparency for diagnostics of clearance and hardness for monitoring by frequency and acoustic resonance duration, graphite conducts an electric current well enough. $10]$.

The choice is due to the offered eddy-current method [9,

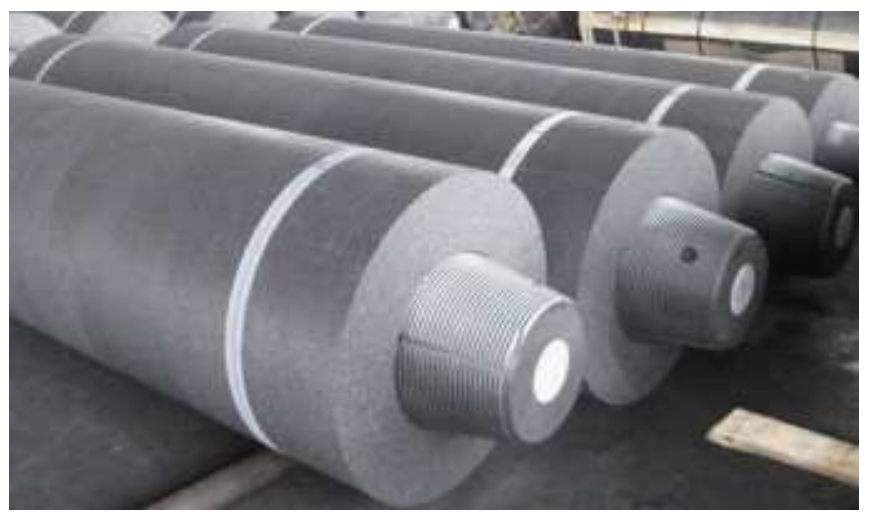

Fig. 1. Electrodes for arc steel smelting furnaces

\section{THEORY}

The technology of manufacturing and transportation of graphite products does not exclude the presence or appearance of defects in the form of cavities and cracks. External defects are relatively easy to detect visually, which can not be said about internal defects. For defectoscopy of graphite electrodes, it is advisable to use more complicated methods [11-14]. The eddy-current method implies a change in the penetration depth by a variation of frequency of test current according to the expression:

$$
\delta=\sqrt{\frac{1}{\pi \cdot f \cdot \mu \cdot \sigma}},
$$

where $\delta$ - depth of current penetration, m;

$$
\begin{aligned}
& f \text { - current frequency, } \mathrm{Hz} ; \\
& \mu=\mu_{0} \cdot \mu_{r} \text { - magnetic conductivity, } \mathrm{H} / \mathrm{m} ; \\
& \sigma \text { - electric conductance, } \mathrm{S} \cdot \mathrm{m} .
\end{aligned}
$$

An electric current penetration into graphite at a depth of $0.5 \mathrm{~m}$, characterizing a 2.71-time loosening of a current density at this depth, requires the frequency of $8 \mathrm{~Hz}$.

When having cavities or foreign nonconducting particulates of a product at some depth, the equivalent conductivity of this section will be changed in proportion to the relation: 


$$
k_{S}=\frac{S-S_{0}}{S}
$$

where $S=\pi \cdot\left(D \cdot \delta-\delta^{2}\right)$ - cross-sectional area of the graphite electrode, streamlined by the main current;

$D$ - outer diameter of the electrode;

$S_{0}$ - cross-sectional area of the foreign inclusion.

From (2) it is seen that in case of occurrence of defect which is close to the center of the electrode, when $\delta \rightarrow D / 2$, the conductance increment with the reduction of frequency of current differs poorly from a similar increment of conductance in the electrode, which does not have defect.

The general factor, considering influence on electric conductivity of a graphite electrode, as well as defect lengths along an electrode axis, is given as follows:

$k=\frac{\sigma_{a}}{\sigma_{0}}=\frac{k_{S} \cdot l+1 \cdot(L-l)}{L}=\frac{L-\left(1-k_{S}\right) \cdot l}{L}$

where $\sigma_{a}$ - equivalent electrical conductivity of a graphite electrode in the presence of a defect;

$\sigma_{0}$ - electric conductivity of a graphite electrode;

$L$ - length of a graphite electrode;

$l$ - defect length along an axis of a graphite core.

So, for example, the defect in the form of a nonconducting cavity of cubic form with a size of $d=0.1 \cdot D$, located in the maximum proximity to a surface of the length of a graphite product, $L=3 \cdot D$, will change its resultant conductivity when diagnosing by the eddy-current method with $\delta=d$ only with $0.11 \%$ :

$$
\begin{aligned}
& k_{S}=\frac{\pi \cdot 0.09 \cdot D^{2}-0.01 \cdot D^{2}}{\pi \cdot 0.09 \cdot D^{2}}=0.9646, \\
& k=\frac{3-(1-0.9646) \cdot 0.1}{3}=0.99882
\end{aligned}
$$

Using in a formula of weight coefficients of lengths $l$ of the defective and not struck sector $L-l$ of a core is true as distribution of currents before and after defect is practically leveled.
The prevention of side redistribution of currents, limited to the cylinder with an internal diameter $D-2 \cdot d$ and external $D$ will be able to strengthen change of electric conductivity according to (2).

It is known that along with skin effect at an arrangement near conductors with opposite directed currents, the effect of proximity takes place according to which there is a replacement of currents on side surfaces. Use of this phenomenon in combination with the eddy-current method implies current density shift in the section of a graphite core by third-party conductors with current. Thus, there is an opportunity of special combination of currents in the metal cores located in close proximity to the studied object to define the diagnosed core sector that considerably increases sensitivity of an eddy-current method, as well as allows one to localize the defect place in graphite.

\section{Simulation}

For receiving a possibility of localization of internal damage place, and also the empowerment of the defect influence on electrical conductance of a graphitized electrode near or around it, there are 6 thin metal rods distant from each other at angle $\pi / 3$. Current in each $\mathrm{N}$-th rod is changed by the function of a sine with changing frequency $f$ and phase $\varphi_{N}:$

$$
I_{N}=I_{m} \cdot \sin \left(2 \cdot \pi \cdot f \cdot t+\varphi_{N}\right)
$$

Electrical conductance is measured with different frequencies of current in it and combinations of currents in metal rods, which set desirable extrusion of current in the graphite rod.

Using the eddy-current method at a frequency of $8 \mathrm{~Hz}$ according to (1) sets, the $0.5 \mathrm{~m}$ penetration depth of current and the effect of closeness, created by metal rods, distorts distribution of a current density on the sector in a transverse section of the rod.

Fig. 2 presents the current distribution of density in a transverse section of the graphite rod with defect at a frequency of $8 \mathrm{~Hz}$. Simulation is executed in a FEMM4.2. Current density distribution in a graphitized electrode, depending on frequency and a phase of currents in rods, is provided in Fig. 3. 


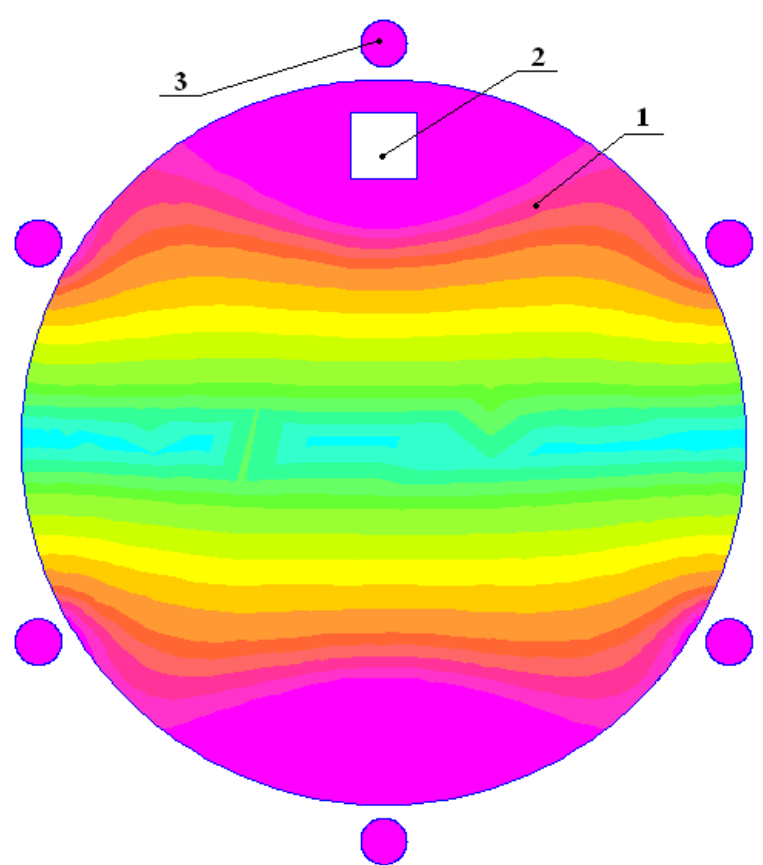

a)

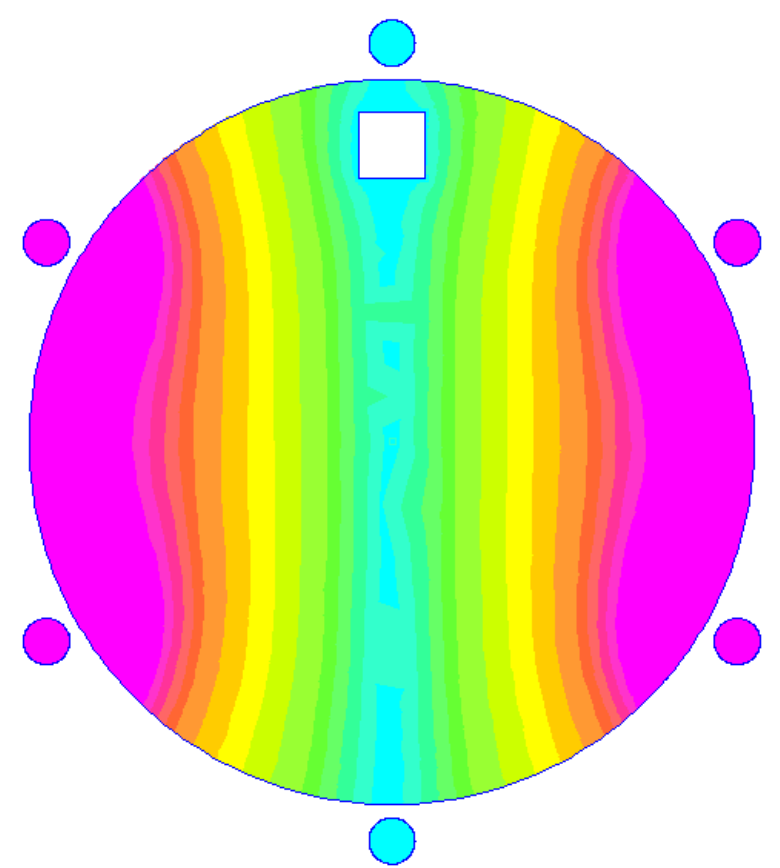

b)

Fig. 2. Current density distribution in a transverse section of an electrode with a frequency of $8 \mathrm{~Hz}$ : a) vertical current density distribution; b) horizontal current density distribution. 1 - Graphite rod. 2 - Place of defect. 3 - The metal rod for current displacement

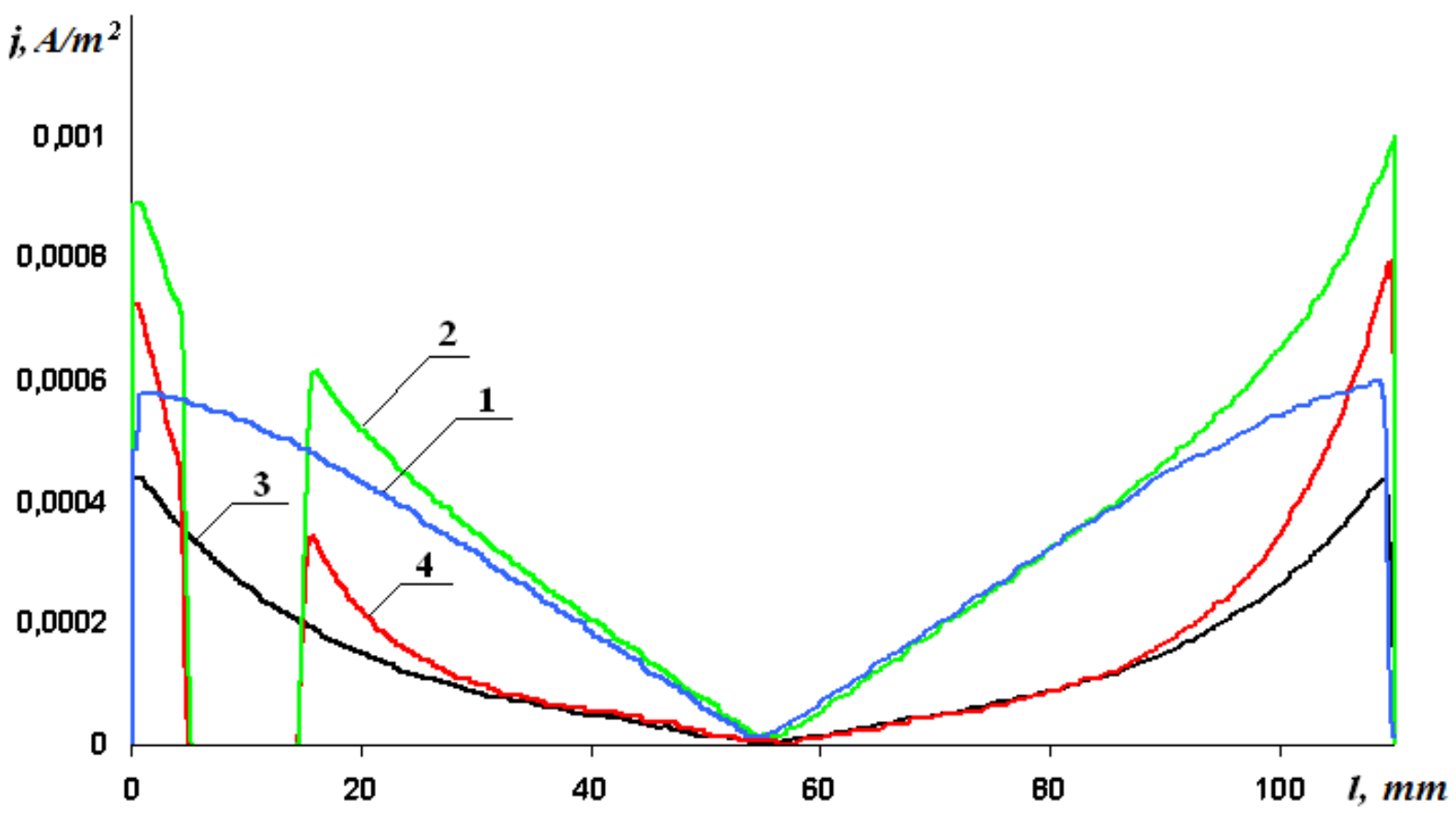

Fig. 3. The diagram of current density distribution in a graphitized electrode: 1 - with a frequency of $8 \mathrm{~Hz}$ and horizontal current density distribution; 2 - with a frequency of $8 \mathrm{~Hz}$ and vertical current density distribution; 3 - with a frequency of $80 \mathrm{~Hz}$ and horizontal current density distribution; 4 - with a frequency of $80 \mathrm{~Hz}$ and vertical current density distribution

Operating with current distribution in an electrode, it is possible to direct electric current in a desirable trajectory so that it crossed serially all areas of a graphite electrode, carrying out scanning. Comparing conductivity of a graphite core when finding the main electric current in various sectors, one can localize the place of damage.

As a result of calculation, it turned out that resistance of a graphitized electrode is equal to 27.07 microOhm if the current density was distributed vertically, as it is shown in Fig. 2 , and it corresponds to the diagram in Fig. 3. In case of horizontal current density distribution (Fig. 2) with the diagram of a current density (Fig. 3) and other equal conditions, the electrode resistance will be 25.27 microOhm. In this work, an eddy-current method was used with the use of the proximity effect at a frequency of $8 \mathrm{~Hz}$. 
As a result of the simulation, the electrical conductivity was determined

$$
\frac{3-(1-0.9335) \cdot 0.1}{3}=0.99778 \text { times or was received for }
$$
$0.22 \%$.

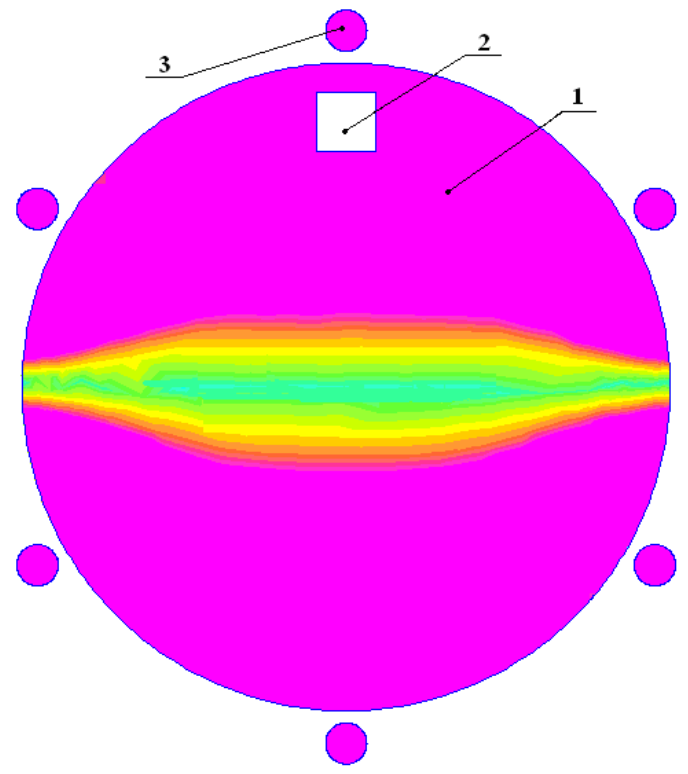

Fig. 4 similarly shows distribution of a current density in a transverse section of the graphite rod defect with a frequency of $80 \mathrm{~Hz}$. Distribution of current density in a graphitized electrode, depending on frequency and a phase of currents in rods, is provided in Fig. 3.
Fig. 4. Current density distribution in a transverse section of an electrode with a frequency of $80 \mathrm{~Hz}$ : a) vertical current density distribution; b) horizontal current density distribution. 1 - Graphite rod. 2 - Place of defect. 3 - The metal rod for current displacement
Further, an eddy-current method was used with the use of the proximity effect at a frequency of $8 \mathrm{~Hz}$.

As a result of the simulation, the electrical conductivity was determined:

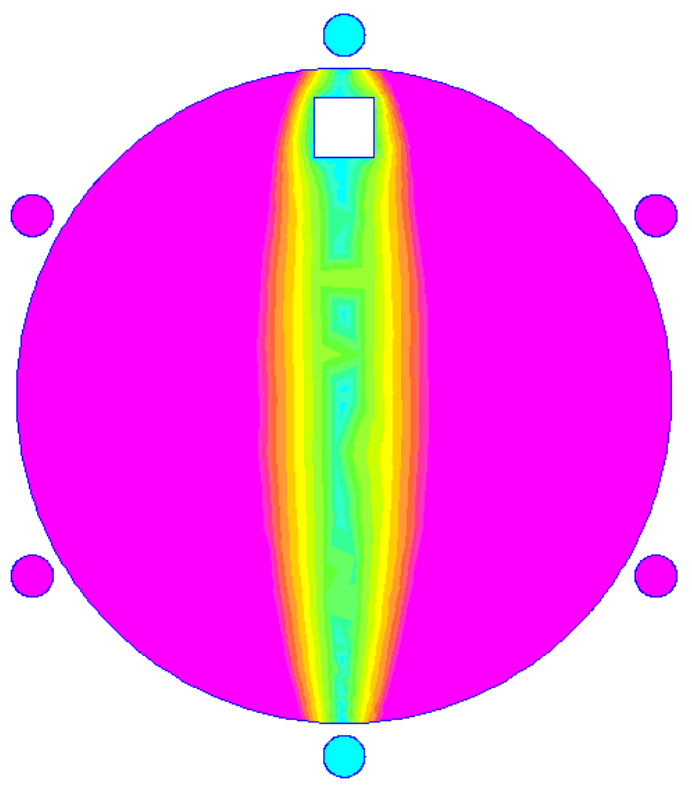

b

\section{EXPERIMENT}

The prototype of the device, the structural diagram of which is shown in Fig. 5, allows detecting internal defects of the graphite electrode.

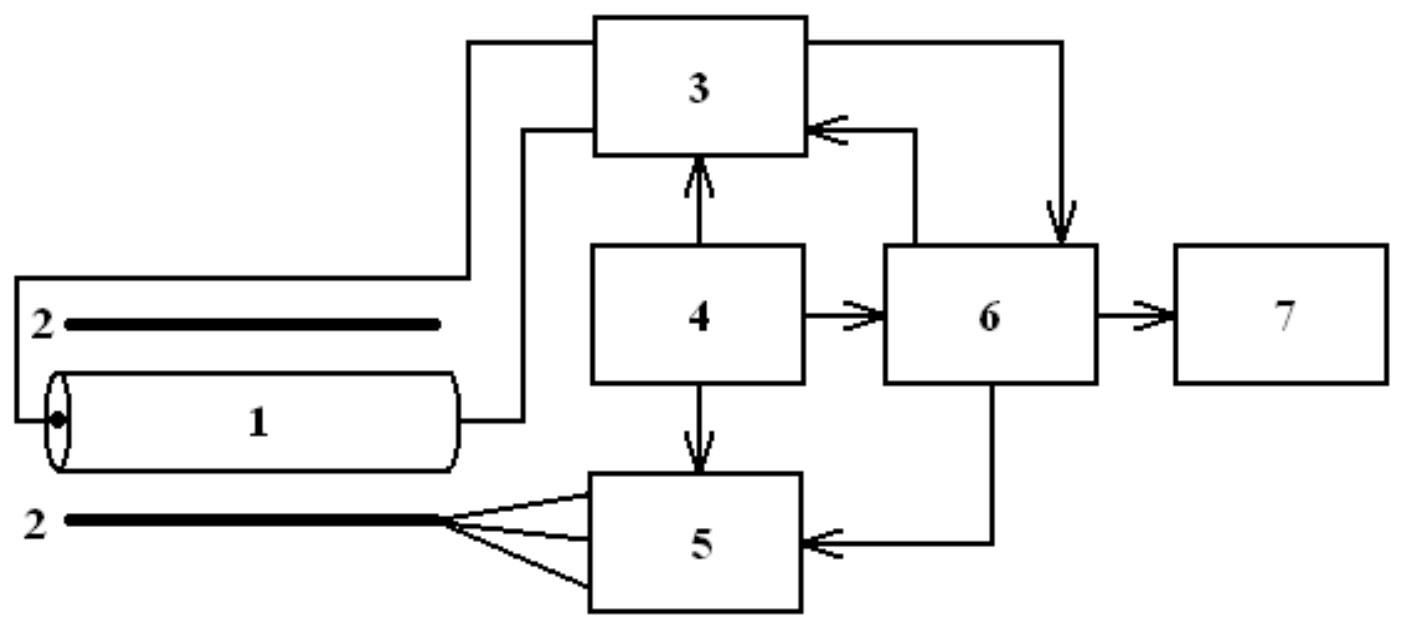

Fig. 5. A block diagram of the device for defectoscopy of electrodes: 1 - graphite electrode; 2 - metal rods; 3 - resistance meter; 4 - power supply; 5 - generator; 6 - microcontroller; 7 - liquid crystal display

According to Fig. 5, generator 5, controlled in the phase by microcontroller 6 , determines the current displacement in electrode 1 by rods 2 . Resistance meter 3 is a sweep-current generator and a synchronous voltmeter, adjusted to zero phase 
shift. Thus, the voltmeter readings are proportional to the resistance of the electrode. The change of the frequency of sweep generator 3 according to the control signal from microcontroller 6 determines the depth of penetration of the current into graphite electrode 1. As a result, for various depths of current penetration, there are arrays of resistances for different phases of the displacement current in rods 2 . The result of the operation of the device displayed on indicator 7 is the coefficient of asymmetry, characterizing the linear size of the defect in relative units, as well as the relative depth of the defect.

The appearance of the device that performs defectoscopy of graphite electrodes is shown in Fig. 6.

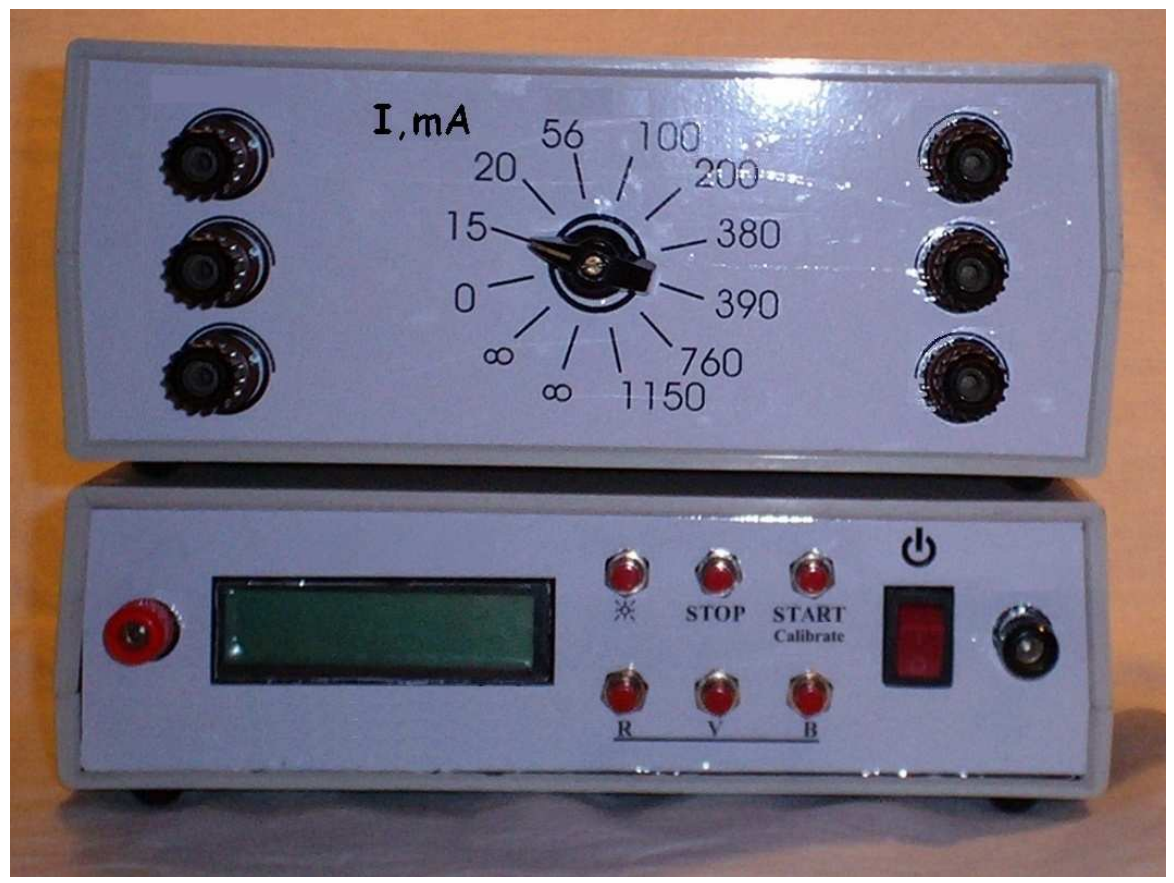

Fig. 6. The digital device for the control of the integrity of graphite electrodes

The generator that shifts the current distribution in the graphite electrode is made of a separate body. This generator is connected to the main unit by a communication cable with a UART RS232 interface; it is shown in Fig. 6 at the top. The operating mode of the device is set by the buttons on the front panel of the main module, located in Fig. 6 below.

\section{CONCLUSIONS}

For quality control of graphite cores, use of the eddycurrent methods has prospects (along with an ultrasonic one). It is shown that the proximity effect with the eddy-current method increases the sensitivity of the recording and measuring means. A device has been developed to detect defects and various inclusions up to several percent of the linear size of the electrode. In comparison with the method of ultrasonic diagnostics [15], which involves sensory scanning of the entire surface, the application of the proposed method helps accelerate the quality control of graphite electrodes.

\section{References}

[1] E. Y. Abramov, N. I. Schurov and M. V. Rozhkova, "Electric transport traction power supply system with distributed energy sources", IOP Conference Series: Materials Science and Engineering, 2016, Vol. 127, $7 \mathrm{p}$.
[2] E.Y. Abramov, A.A. Stang and S.A. Enkudinov, "Transformation of the urban electric transport system when using autonomous energy sources", Advanced Materials Research, 2014, Vol. 1040, pp. 778-783.

[3] V.I. Sopov, N.I. Schurov, Y.A. Prokushev and A.A. Shtang, "Increasing the efficiency of the use of electrical energy in the sub-subsystem of electric transport (Povishenie effektivnosti ispol'zovaniya elektricheskoy energii v subpodsisteme elektricheskogo transporta)", Improvement of technical means of electric transport (Sovershenstvovanie tehnicheskih sredstv elektricheskogo transporta), 2002, 189 p. [Digest of scientific works of the NSTU]

[4] B.A. Arzhannikov and A.A. Pyshkin, "Improving of DC power supply system based on automatic voltage regulation of traction substations (Sovershenstvovanie sistemi elektrosnabzheniya postoyannogo toka na osnove avtomaticheskogo regulirovaniya napryazheniya tyagovih podstanciy)", Ekaterinburg: "USURT Press", 2006, 116 p.

[5] V.I.Sopov, V.V. Biryukov, Y.A. Prokushev and Y.A. Rylov, "Analysis of power supply systems for rolling stock with various schemes of traction networks (Analiz sistem elektrosnabzheniya podvizhnogo sostava s razlichnimi shemami tyagovih setey)", Transport, Science, Engineering, Management (Transport, Nauka, Technika, Upravlenie). Vol. 2 (2008), pp. 49-53. [Digest of the VINITI RAS]

[6] V.V. Biryukov and A.V. Kulekina, "The calculation features of the electrical energy storage devices parameters in transport", The 11 International forum on strategic technology (IFOST 2016), pp. 41-43.

[7] N.I. Schurov, E.A. Spiridonov and A.V Larin, "Modes of traction power supply system in case of electric rolling stock equipped with energy storage", Applied Mechanics and Materials, 2014, Vol. 698, pp. 19-23.

[8] Photovoltaic (PV) research: National Renewable Energy Laboratory (NREL). Retrieved on http://www.nrel.gov/ncpv. 
[9] N.W.A. Lidula and A.D. Rajapakse, "Microgrids research: a review of experimental microgrids and test systems", Renewable and Sustainable Energy Reviews, 2011, Vol. 15, pp. 186-202.

[10] B. Kroposki, R. Lasseter, T. Ise, S. Morozumi, S. Papathanassiou and N. Hatziargyriou, "A look at microgrid technologies and testing projects from around the world, making microgrids work", IEEE Power and Energy Magazine, 2008, Vol. 6, pp. 40-53.

[11] V.E. Rozenfeld, "Analytical calculation of electric railway networks (Analiticheskiy raschet setey elektricheskih zheleznih dorog)", The theoretical and scientific-practical peer-reviewed journal "Elektrichestvo", 1947, Vol. 9, pp. 6-17. 